\title{
Value of PAX8, PAX2, napsin A, carbonic anhydrase IX, and claudin-4 immunostaining in distinguishing pleural epithelioid mesothelioma from metastatic renal cell carcinoma
}

\author{
Nelson G Ordóñez \\ Department of Pathology, The University of Texas MD Anderson Cancer Center, Houston, TX, USA
}

\begin{abstract}
Both mesotheliomas and renal cell carcinomas can present a wide variety of cytomorphologic features and histologic patterns. Because of this, renal cell carcinomas metastatic to the pleura and lung can be confused with mesotheliomas. Recently, a variety of positive carcinoma markers, including kidney-associated markers, have become available. The aim of this study is to investigate the value of some of these markers, specifically PAX8, PAX2, napsin A, carbonic anhydrase IX, and claudin-4, for assisting in distinguishing pleural epithelioid mesotheliomas from metastatic renal cell carcinomas. To do so, a total of 40 pleural epithelioid mesotheliomas and 55 renal cell carcinomas (33 clear cell, 10 papillary, and 12 chromophobe) were investigated. In all, $91 \%$ of the renal cell carcinomas expressed claudin-4, 89\% PAX8, 60\% PAX2, 71\% carbonic anhydrase IX, and $29 \%$ napsin A. All of the mesotheliomas were positive for carbonic anhydrase IX and were negative for all of the other markers. On the basis of these results, it is concluded that claudin-4 and PAX8 have a higher sensitivity and specificity for assisting in discriminating between pleural epithelioid mesotheliomas and renal cell carcinomas when compared with all of the other positive carcinoma markers that are, at present, recommended to be included in the immunohistochemical panels used in this differential diagnosis. Even though PAX2 and napsin A are highly specific, because of their low sensitivity, they have only a limited value. Carbonic anhydrase IX is not useful.

Modern Pathology (2013) 26, 1132-1143; doi:10.1038/modpathol.2013.34; published online 15 March 2013
\end{abstract}

Keywords: carbonic anhydrase IX; claudin-4; immunohistochemistry; mesothelioma; napsin A; PAX2; PAX8; renal cell carcinoma

Characteristically, mesotheliomas can present a diverse array of cytomorphologic features and grow in a wide variety of histologic patterns. Because of this, they can be easily confused with a number of other malignancies that can involve the serosal membranes. Although the majority of published studies investigating the role of immunohistochemistry in the diagnosis of these tumors have focused primarily on the distinction between pleural epithelioid mesotheliomas and lung adenocarcinomas, ${ }^{1-7}$ only a few have looked into discriminating between

Correspondence: Dr NG Ordóñez, MD, Department of Pathology, The University of Texas MD Anderson Cancer Center, 1515 Holcombe Boulevard, Houston, TX 77030, USA.

E-mail: nordonez@mdanderson.org

Received 21 October 2012; revised 12 December 2012; accepted 28 December 2012; published online 15 March 2013 pleural epithelioid mesotheliomas and renal cell carcinomas. ${ }^{8-10}$ Renal cell carcinomas, like mesotheliomas, can also exhibit numerous histologic patterns, some of which can be confused with some morphologic variants of mesothelioma. ${ }^{11,12}$ In addition, renal cell carcinomas can also mimic mesotheliomas, both clinically and radiologically, as they frequently metastasize to the lung and pleura, occasionally encase the lung, and sometimes occur in the absence of a known renal tumor or urologic symptoms. ${ }^{13-17}$ Furthermore, cases of renal cell carcinomas have been reported in individuals exposed to asbestos and examples of concomitant renal cell carcinoma and mesothelioma have been documented in the literature. ${ }^{18,19}$ Finally, distant visceral metastases, which can sometimes occur as a single mass, are not rare in pleural mesotheliomas, and one of the most frequently involved organs is 
the kidney. ${ }^{20}$ In recent years, a wide variety of immunohistochemical markers, including kidneyassociated markers that can assist in the diagnosis and classification of renal epithelial tumors, have become available. ${ }^{21}$ Little information exists, however, regarding the expression of these markers in mesotheliomas or on their value in assisting in discriminating these tumors from renal cell carcinomas. The purpose of this study is to determine the practical utility of some of these markers, specifically PAX8, PAX2, napsin A, carbonic anhydrase IX (CA IX), and claudin-4 (CL4), for assisting in distinguishing between pleural epithelioid mesotheliomas and metastatic renal cell carcinomas and to compare them with other renal cell carcinoma markers that have previously been recommended as being useful in facilitating this differential diagnosis.

\section{Materials and methods}

The material used in this study was obtained from the files of the Department of Pathology at The University of Texas MD Anderson Cancer Center. It consisted of 40 pleural epithelioid mesotheliomas and 55 renal cell carcinomas. In all of the mesothelioma cases, the diagnosis was confirmed by the use of histologic and immunohistochemical criteria combined with clinical and radiologic information. Of the 55 renal cell carcinomas, 33 were clear cell (22 metastatic, 11 primary), 10 papillary, and 12 chromophobe renal cell carcinomas. Immunohistochemical studies were performed on $5-\mu \mathrm{m}$-thick, formalin-fixed, paraffin-embedded tissue sections using the polymeric biotin-free horseradish peroxidase method on a Leica Microsystems Bond Max Stainer (Bannockburn, IL, USA). The primary antibodies are listed in Table 1. In brief, slides were deparaffinized and hydrated, followed by heatinduced antigen retrieval in which a citrate buffer solution, $\mathrm{pH}$ 6.0, was used. Incubation with the primary antibody was followed by development of the immunostaining with $3,3^{\prime}$-diaminobenzidine. The secondary antibody and detection was applied as per the manufacturer's instructions. To evaluate the specificity of the immunoreaction, known positive and negative tissues were used as controls. The immunostaining was graded on a sliding scale of $1+$ to $4+$ according to the percentage of reactive cells $(1+, 1-25 \% ; 2+, 26-50 \% ; 3+, 51-75 \%$; and $4+,>75 \%)$.

\section{Results}

The immunohistochemical results are summarized in Table 2.

\section{PAX8}

Of the 55 renal cell carcinomas, 49 (89\%) demonstrated PAX8 nuclear positivity, including 31 (94\%) of 33 clear cell, $10(100 \%)$ of 10 papillary, and 9 $(75 \%)$ of 12 chromophobe (Figures 1a-c). The reaction was strong and diffuse $(3+$ or $4+)$ in the 31 clear cell, 8 of the papillary, and 4 of the chromophobe renal cell carcinomas, and focal $(1+$ or $2+$ ) in the remaining cases. All of the mesotheliomas were PAX8 negative.

\section{PAX2}

In all, $33(60 \%)$ of the 55 renal cell carcinomas exhibited PAX2 positivity. In total, 23 of the positive cases were clear cell, 6 papillary, and 4 chromophobe. The staining in these cases was strong $(3+$ or $4+$ ) in 7 of the clear cell, 3 of the papillary, and 2 of the chromophobe renal cell carcinomas (Figure 1d), whereas in the remaining cases, it was focal $(1+$ or $2+)$. None of the mesotheliomas expressed PAX2.

\section{Napsin A}

Only $8(24 \%)$ of the 33 clear cell and $7(70 \%)$ of the 10 papillary renal cell carcinomas, but none of the

Table 2 Immunohistochemical results in renal cell carcinoma

\begin{tabular}{lcccccc}
\hline & & $\begin{array}{c}\text { PAX8 } \\
+(\%)\end{array}$ & $\begin{array}{c}\text { PAX2 } \\
+(\%)\end{array}$ & $\begin{array}{c}\text { Napsin A } \\
+(\%)\end{array}$ & $\begin{array}{c}\text { CA IX } \\
+(\%)\end{array}$ & $\begin{array}{c}\text { Claudin-4 } \\
+(\%)\end{array}$ \\
\hline Clear cell & 33 & $31(94)$ & $23(70)$ & $8(24)$ & $32(97)$ & $28(85)$ \\
Papillary & 10 & $10(100)$ & $6(60)$ & $7(70)$ & $7(70)$ & $10(100)$ \\
Chromophobe & 12 & $9(75)$ & $4(33)$ & $0(0)$ & $0(0)$ & $12(100)$ \\
Total & 55 & $49(89)$ & $33(60)$ & $15(28)$ & $39(71)$ & $50(91)$
\end{tabular}

Table 1 Antibodies used in this study

\begin{tabular}{|c|c|c|c|c|}
\hline Marker & Source & Type & Dilution & Antigen retrieval \\
\hline Carbonic anhydrase IX & Novocastra (Buffalo Grove, IL, USA) & TH22 MAb & $1: 100$ & Yes (citrate) \\
\hline Claudin-4 & Invitrogen (Camarillo, CA, USA) & 3E2C1 MAb & $1: 250$ & Yes (citrate) \\
\hline Napsin A & Novocastra & IP64 MAb & $1: 300$ & Yes (citrate) \\
\hline PAX2 & Invitrogen & Z-RX2 PAb & $1: 25$ & Yes (citrate) \\
\hline PAX8 & ProteinTech Group (Chicago, IL, USA) & PAb (rabbit) & $1: 100$ & Yes (citrate) \\
\hline
\end{tabular}

Abbreviations: MAb, monoclonal antibody; PAb, polyclonal antibody. 

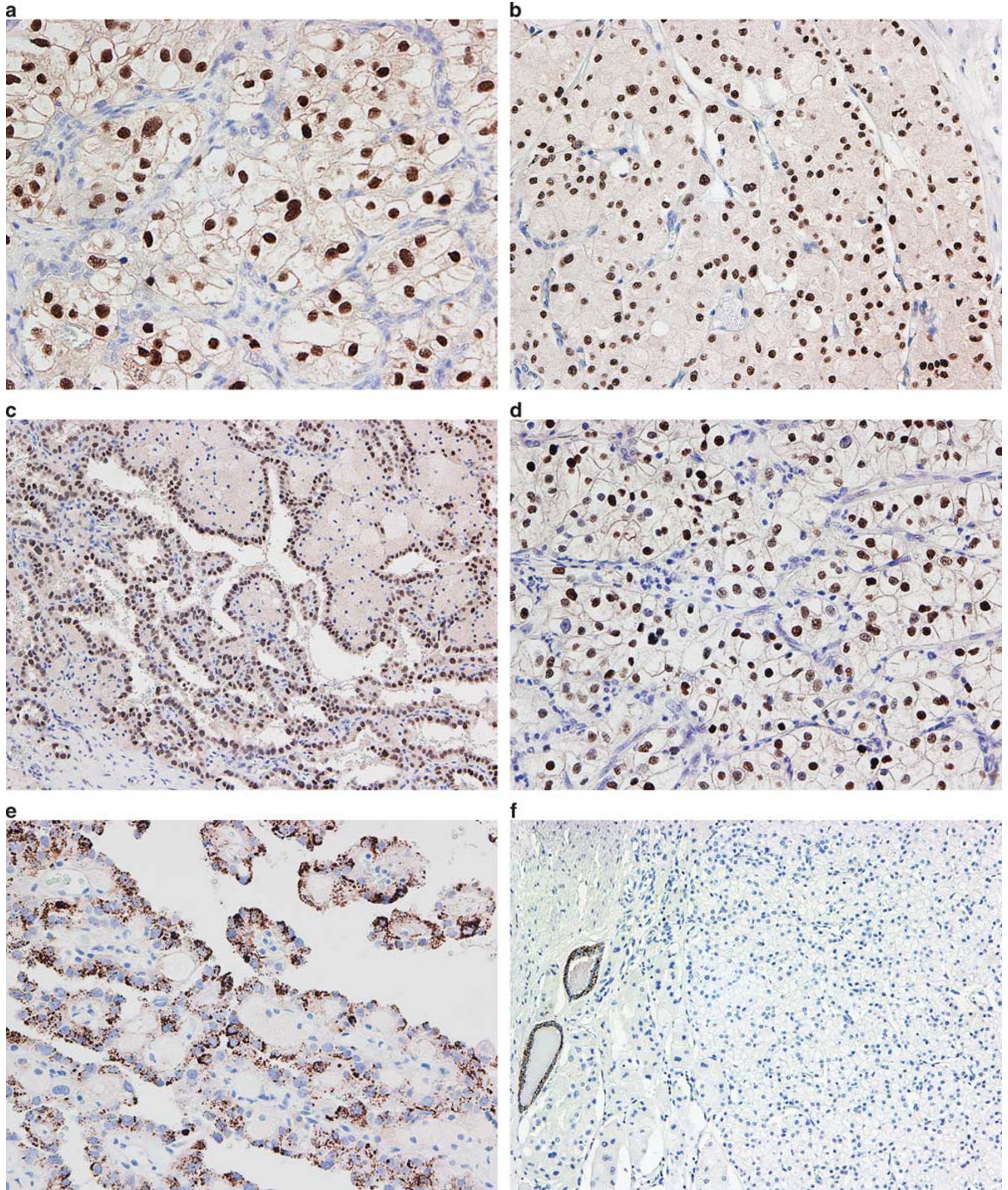

Figure 1 (a) Clear cell carcinoma exhibiting strong nuclear positivity for PAX8. (b) Chromophobe renal cell carcinoma displaying nuclear positivity for PAX8. (c) Papillary renal cell carcinoma showing nuclear PAX8 reactivity. (d) Clear cell renal cell carcinoma exhibiting PAX2 nuclear positivity. (e) Papillary renal cell carcinoma showing cytoplasmic positivity for napsin A. (f) Chromophobe carcinoma demonstrating a lack of napsin A expression in the neoplastic cells. Strong positivity for this marker is seen in two atrophic nonneoplastic renal tubules (left).

12 chromophobe renal cell carcinomas, were napsin A positive (Figures 1e and f). The staining in these cases was granular and cytoplasmic, and it was strong $(3+$ or $4+)$ in 4 of the 8 clear cell and in all 7 of the positive papillary renal cell carcinomas. In the remaining 4 clear cell renal cell carcinomas, the 
reactivity was focal $(1+$ or $2+)$. No immunoreactivity was seen in any of the mesotheliomas.

\section{Carbonic Anhydrase IX}

CA IX expression was demonstrated in 32 (97\%) of 33 clear cell and 7 (70\%) of 10 papillary, but in none of the 12 chromophobe renal cell carcinomas. The staining in these cases occurred along the cell membrane and was strong $(3+$ or $4+)$ in the 32 clear cell and in 3 of the papillary renal cell carcinomas (Figure 2a). All 40 of the epithelioid mesotheliomas expressed CA IX (Figure 2b). In 28 of the cases, the staining was strong and diffuse $(3+$ or $4+)$, whereas it was focal $(1+$ or $2+)$ in the remaining cases.

\section{Claudin-4}

In all, $51(91 \%)$ of the 55 renal cell carcinomas exhibited CL-4 expression, including 28 (85\%) of 33 clear cell, 10 of 10 papillary, and 12 of 12 chromophobe renal cell carcinomas. The staining in these cases occurred along the cell membrane in a continuous or punctuated pattern, and it was strong and diffuse $(3+$ or $4+)$ in the majority of clear cell (20 of the cases), and in all of the papillary and chromophobe renal cell carcinomas (Figures 2c-f). None of the mesotheliomas showed CL-4 positivity.

\section{Discussion}

Because an absolutely sensitive and specific marker for either mesothelioma or renal cell carcinoma has not yet been identified, establishing the differential diagnosis between these two malignancies largely depends on the use of immunohistochemical panels composed of positive mesothelioma markers (ie, those that are frequently expressed in mesotheliomas, but not in carcinomas) and positive carcinoma markers (ie, those that are frequently expressed in carcinomas, but not in mesotheliomas). To my knowledge, only three studies have been published comparing the value of a relatively large number of immunohistochemical markers for assisting in discriminating between mesotheliomas and metastatic renal cell carcinomas. ${ }^{8-10}$ The first of these studies was conducted by Attanoos et $a l^{8}$ in 1995, who evaluated the diagnostic utility of CD15 (Leu-M1), Ber-EP4, Tamm-Horsfall protein, and thrombomodulin for assisting in the differential diagnosis between renal cell carcinomas and mesotheliomas. ${ }^{8}$ The conclusion of that investigation was that only thrombomodulin and CD15 were useful in discriminating between renal cell carcinomas and epithelioid mesotheliomas; however, these two markers had no value in distinguishing between sarcomatoid mesotheliomas and sarcomatoid renal cell carcinomas. ${ }^{8}$ The second study was conducted by Osborn et $\mathrm{al}^{9}$ in 2002, who investigated the value of calretinin, keratin 5/6, thrombomodulin, CEA, Ber-EP4, and BCA225 immunostaining in discriminating metastatic renal cell carcinomas from mesotheliomas. Based on the results of that study, the authors concluded that calretinin, keratin 5/6, and Ber-EP4 were the most useful markers for assisting in this differential diagnosis. In the third study, which was by this author in 2004, the expression of a large number of positive mesothelioma markers (calretinin, mesothelin, keratin 5/6, WT1, thrombomodulin, and $\mathrm{N}$-cadherin) and positive carcinoma markers (Ber-EP4, MOC-31, CD15, BG8 (Lewis ${ }^{\mathrm{y}}$ ), TAG-72 (B72.3), CEA, renal cell carcinoma marker (RCC Ma) and CD10) was investigated. ${ }^{10}$ The conclusion of that investigation was that calretinin, mesothelin, and keratin 5/6 were the best positive mesothelioma markers, and CD15, MOC-31, and RCC Ma were the best positive carcinoma markers for discriminating between epithelioid mesotheliomas and renal cell carcinomas.

In recent years, a relatively large number of markers whose expression is considered to be somewhat restricted to the kidney and renal cell carcinomas have become available. These renal-associated markers include PAX8, PAX2, napsin A, CA IX, RCC Ma, and CD10. Very few studies have been published on the expression of these markers in mesotheliomas and on their value in assisting in distinguishing these tumors from renal cell carcinomas.

PAX8 is a transcription factor that, during embryogenesis, plays an important role in the development of several organs, including the kidney, thyroid, certain areas of the nervous system, and organs derived from the mesonephric (Wolffian) duct and those related to the Müllerian duct. ${ }^{22,23}$ The percentage of PAX8 positivity reported in various types of renal cell carcinomas has ranged from $91-98 \%$ for clear cell, $71-100 \%$ for papillary, and $57-88 \%$ for chromophobe. ${ }^{24-26}$ It has also been reported to be expressed in the vast majority (83$100 \%$ ) of metastatic clear cell renal cell carcinomas, regardless of their degree of differentiation ${ }^{24,26-29}$ and in $100 \%{ }^{24,25}$ of the metastatic papillary renal cell carcinomas investigated. These results are comparable with those of the present investigation in which 10 (91\%) of 11 primary and 21 (95\%) of 22 metastatic clear cell, 10 (100\%) of 10 papillary, and $9(75 \%)$ of 12 chromophobe renal cell carcinomas were found to express PAX8. Only one study has been published on PAX8 expression in epithelioid mesotheliomas. ${ }^{30}$ In that investigation, PAX8 positivity was demonstrated in 2 (9\%) of 23 peritoneal epithelioid mesotheliomas, but none was found in any of the 24 pleural epithelioid mesotheliomas included in the study. In the present investigation, none of the 40 pleural epithelioid mesotheliomas that were stained for PAX8 were positive. This finding indicates that, because PAX8 is usually absent in mesotheliomas, this marker could be very useful for assisting in 


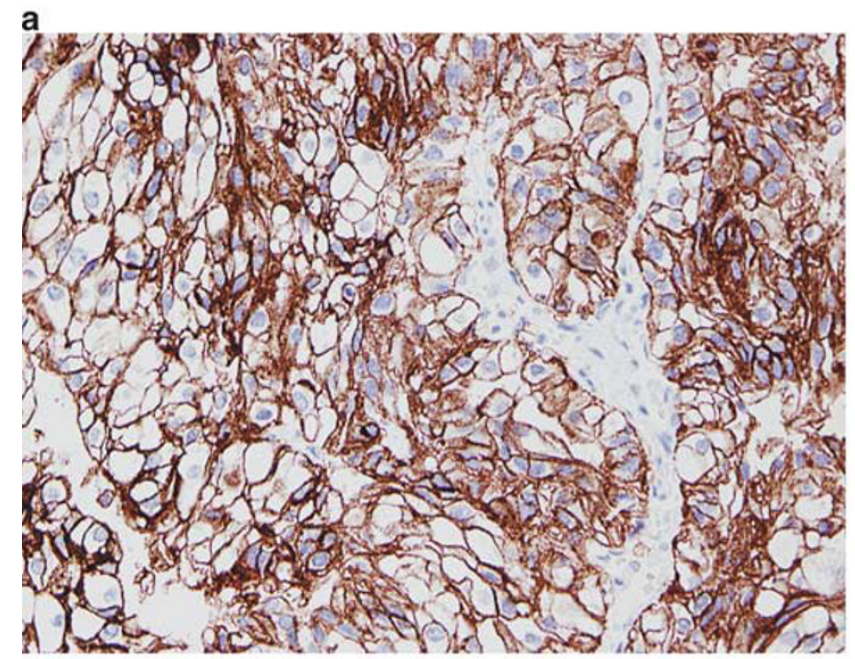

b
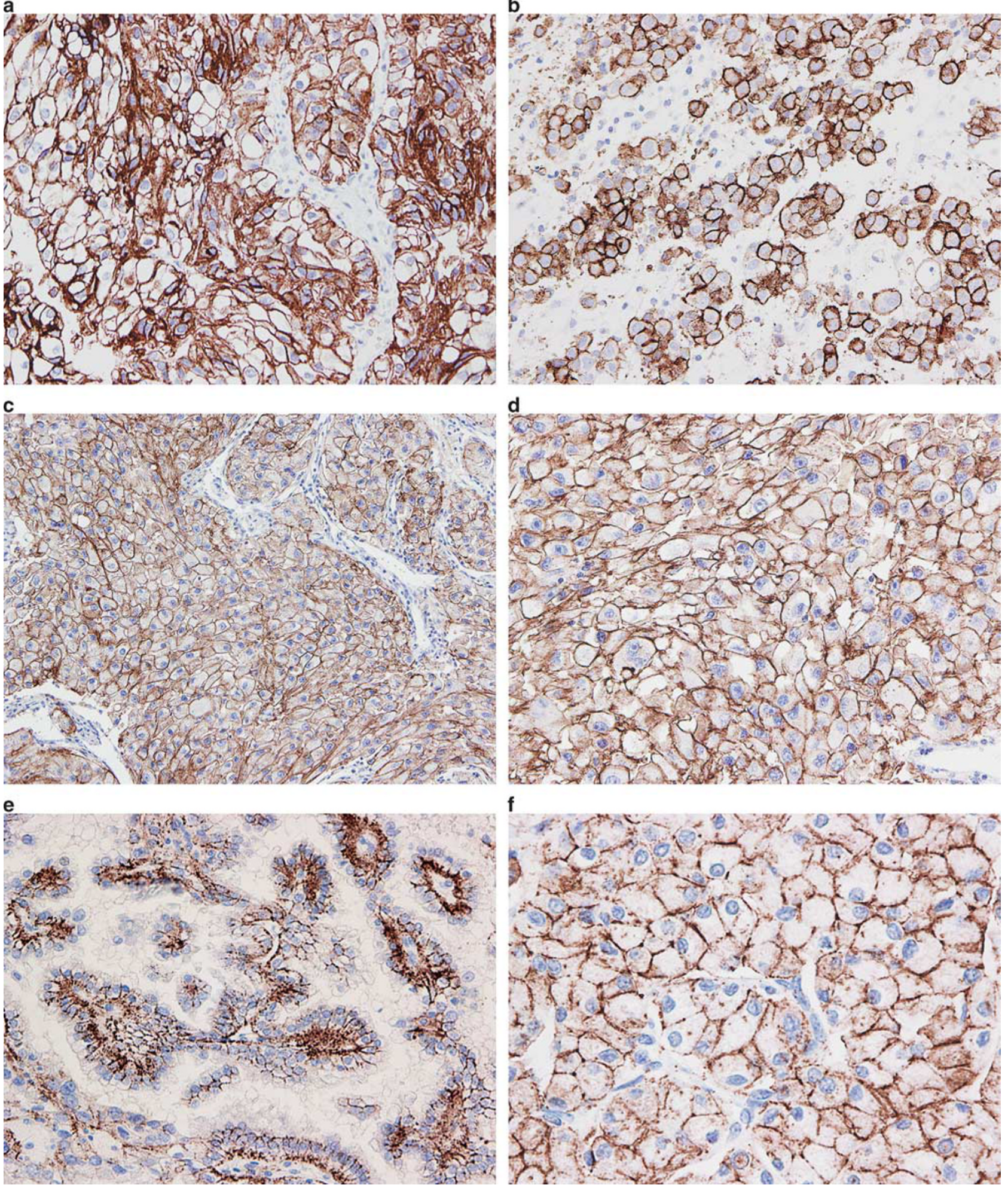

f

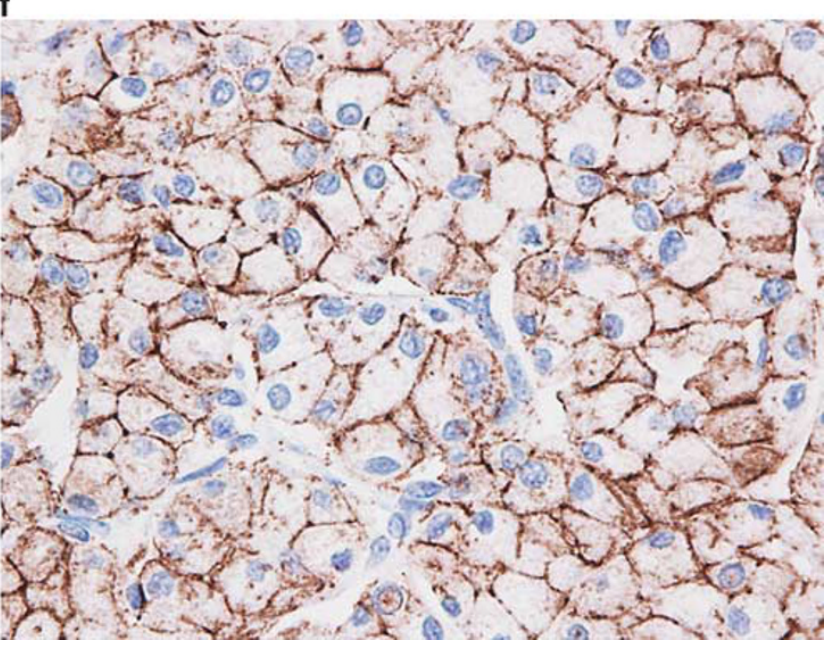

Figure 2 (a) Clear cell renal cell carcinoma displaying strong membranous staining for carbonic anhydrase IX. (b) Epithelioid mesothelioma reacting for carbonic anhydrase IX. (c) Clear cell renal cell carcinoma exhibiting diffuse positivity for claudin-4. (d) Higher magnification showing continuous membranous staining for claudin-4. (e) Papillary renal cell carcinoma reacting for claudin-4. (f) Higher magnification of a chromophobe renal cell carcinoma demonstrating a punctated staining for claudin-4 along the cell membrane.

distinguishing these tumors from metastatic renal cell carcinomas in those instances in which the differential diagnosis is difficult on routine light microscopy. It should be mentioned, however, that even though PAX8 is regarded as a renal cell carcinoma-associated marker, it is not specific for 
this type of tumor as it can also be expressed in other carcinomas, particularly those originating in the thyroid, ovary (non-mucinous carcinomas), endometrium, and thymus. ${ }^{31}$

PAX2 is another transcription factor that, similar to PAX8, is involved in the development of the central nervous system, kidney, and organs related to the Müllerian system. ${ }^{32,33}$ PAX2 has been reported to be expressed in all types of renal cell carcinomas, except urothelial cell carcinomas. ${ }^{34-36}$ The percentage of PAX2 positivity reported in various types of renal cell carcinomas has ranged from 50 to $93 \%$ for clear cell, ${ }^{34-41} 18$ to $100 \%$ for papillary, $34,35,37,38,40-42$ and 6 to $83 \%$ for chromophobe. ${ }^{35-38,40,41}$ It has also been reported to be frequently expressed in metastatic clear cell carcinomas $(49-85 \%) .{ }^{28,29,36,43,44}$ These results are comparable with those of the present investigation in which $7(64 \%)$ of 11 primary and $16(73 \%)$ of 22 metastatic clear cell, $6(60 \%)$ of 10 papillary, and 4 $(33 \%)$ of 12 chromophobe renal cell carcinomas were found to be PAX2 positive. The sensitivity of PAX2, when compared with that of PAX8, is lower as $60 \%$ and $89 \%$ of all renal cell carcinomas were positive for these markers, respectively (Table 2). Because all of the PAX2-positive cases were also positive for PAX8 and the staining for the latter marker was often stronger, immunostaining for both markers does not appear to be necessary. To my knowledge, only one study has been published on PAX2 expression in mesotheliomas. ${ }^{45}$ In that study, PAX2 positivity was demonstrated in $2(12 \%)$ of 17 peritoneal mesotheliomas in women, whereas all 37 peritoneal mesotheliomas in men were negative for this marker. That PAX2 was negative in all of the 40 pleural epithelioid mesotheliomas in the present investigation is an indication that this marker is usually absent in these tumors. It should be mentioned that, similar to PAX8, PAX2 is also considered to be a renal cell carcinoma-associated marker, but as in the case of PAX8, it is not specific for this type of tumor as it can be expressed in some neoplasms of the female genital tract, particularly non-mucinous carcinoma of the ovary and endometrial adenocarcinomas. ${ }^{46}$

Napsin A is an aspartic proteinase that is predominantly expressed in the lung and kidney. ${ }^{47}$ In the kidney, it is expressed in the proximal tubules, where it is thought to function as a lysosomal proteinase in protein catabolism. ${ }^{48}$ Recent investigations have shown that in tumors, napsin A expression is largely restricted to lung adenocarcinomas and renal cell carcinomas, especially the clear cell and papillary subtypes. The percentage of napsin A positivity reported in clear cell and papillary renal cell carcinomas has ranged from $17 \%$ to $43 \%$ and from $75 \%$ to $80 \%$, respectively. ${ }^{49-52}$ Only $1(3 \%)$ of 38 chromophobe carcinomas investigated in two published studies was reported to be napsin A positive. ${ }^{50,52}$ Mesotheliomas have been consistently negative for this marker. ${ }^{50,53-55}$ That only 8 (24\%) of 33 clear cell and $7(70 \%)$ of 10 papillary renal cell carcinomas, but none of the mesotheliomas, in this study were found to express napsin A is an indication that, even though this marker is highly specific in distinguishing these two subtypes of renal cell carcinomas from mesotheliomas, its sensitivity is low, as only a relatively small percentage of clear cell $(24 \%)$ and papillary $(70 \%)$ renal cell carcinomas were napsin A positive.

CA IX is a transmembrane, zinc-containing metalloenzyme that catalyzes the reversible hydration of carbon dioxide into carbonic acid ${ }^{56}$ CA IX is thought to play a role in the adaptation of tumors to hypoxic conditions by regulating the intracellular and extracellular $\mathrm{pH} .{ }^{57,58}$ It is also believed to play a role in the control of cell proliferation, cell transformation, and tumor cell progression. ${ }^{58}$ Because CA IX has been reported to be frequently expressed in renal cell carcinomas, especially the clear cell type, it is, at present, considered to be a diagnostic marker for clear cell renal cell carcinomas. ${ }^{59-64}$ The percentage of CA IX reported in various types of renal cell carcinomas has ranged from 50 to $100 \%$ for clear cell, ${ }^{35,41,62-68} 23$ to $100 \%$ for papillary, $35,41,62,64,66$ and 0 to $31 \%$ for chromophobe. ${ }^{35,41,62,64,66}$ It has also been reported to be frequently expressed in metastatic clear cell renal cell carcinomas (100\%). ${ }^{69}$ CA IX, however, is not a specific marker for renal cell carcinomas as it has also been reported to be expressed in other malignancies, including carcinomas of the lung, breast, stomach, and colon. ${ }^{70}$ Since, in this study, 32 $(97 \%)$ of 33 clear cell and $7(70 \%)$ of 10 papillary renal cell carcinomas, as well as all 40 epithelioid mesotheliomas, that were investigated were found to express CA IX, immunostaining for this marker has no utility for assisting in distinguishing between epithelioid mesotheliomas and metastatic renal cell carcinomas.

Renal cell carcinoma marker is the term used to designate a $200 \mathrm{kDa}$ glycoprotein that is present along the brush border of the pars convoluta and pars recta segments of the proximal tubule, but it is absent in most other normal tissues. ${ }^{71}$ Although RCC Ma expression has been reported in all types of renal cell carcinomas, it is more frequently expressed in clear cell $(\sim 40-85 \%)^{10,71-77}$ and papillary $(\sim 50-95 \%)^{40,42,72,74,76-79}$ renal cell carcinomas. This marker has also been reported in a large percentage of metastatic renal cell carcinomas $(\sim 40-85 \%) .{ }^{43,68,71,75,76,79}$ It should be emphasized, however, that RCC Ma is not absolutely specific for these tumors as it can be expressed in other malignancies, including embryonal carcinomas, ${ }^{74,80}$ adenocarcinomas of the breast, ${ }^{71,74,76}$ prostate and colon, ${ }^{76}$ adrenal cortical carcinomas, ${ }^{76}$ and mesotheliomas. ${ }^{10,75}$ Only two studies have been published on RCC Ma expression in mesotheliomas. ${ }^{10,75}$ The first was by this author who reported focal RCC Ma positivity in 
3 (8\%) of 40 epithelioid mesotheliomas and concluded that this marker should be included in the panel used to distinguish these tumors from metastatic renal cell carcinomas. ${ }^{10}$ The second was by Butnor et al, ${ }^{75}$ who reported RCC Ma expression in $39(26 \%)$ of 145 mesotheliomas. Because the staining was often focal, these authors concluded that strong, diffuse staining for RCC Ma, together with a similar reaction for CD10, would support the diagnosis of metastatic renal cell carcinoma over mesothelioma.

CD10 is a cell surface metalloendopeptidase that was originally named common acute lymphoblastic leukemia antigen as it was first identified in acute lymphoblastic leukemia. ${ }^{81}$ Subsequent investigations demonstrated CD10 expression in a variety of non-hematopoietic tumors, including endometrial stromal sarcomas, ${ }^{82}$ hepatocellular carcinomas, $^{83}$ and renal cell carcinomas. ${ }^{72,84}$ Because of its frequent and somewhat restricted expression in the latter tumors, CD10 is often regarded as a renal cell carcinoma-associated marker, even though it is not specific for these tumors. CD10 is expressed in all subtypes of renal cell carcinomas, including clear cell $(\sim 80-100 \%),{ }^{10,72,77,78,84-86}$ papillary $(\sim 65-100 \%), 41,72,77,78,84-87$ and chromophobe $(\sim 40-65 \%){ }^{10,77,78,85,88}$ Only a few studies have been published on the expression of CD10 in mesotheliomas. ${ }^{10,75,78}$ The percentage of CD10 positivity reported in these tumors has ranged from 18 to $54 \%$ of the cases investigated. ${ }^{10,75,78}$ In a previous study by this author, $39(81 \%)$ of 48 renal cell carcinomas and $19(47 \%)$ of 40 epithelioid mesotheliomas were found to express CD10. ${ }^{10}$ The conclusion of that investigation was that CD10 immunostaining has no utility is discriminating between epithelioid mesotheliomas and metastatic renal cell carcinomas.

CL-4 is a transmembrane protein located within the tight junctions that is widely expressed in most epithelial cells, including those of the kidney, lung, breast, prostate, thyroid, thymus and bladder, but not in hepatocytes or mesothelial cells. ${ }^{89}$ Because CL-4 is frequently expressed in a wide variety of carcinomas, including adenocarcinomas of the lung, breast, ovary, and kidney, as well as in most squamous and transitional cell carcinomas, but it is often absent in epithelioid mesotheliomas, ${ }^{89,90}$ it can be regarded as a broad-spectrum positive carcinoma marker. ${ }^{91}$ In 2006, Soini et al ${ }^{90}$ were the first to investigate CL-4 expression in mesotheliomas and to examine its potential utility for assisting in the differential diagnosis of these tumors. In that study, 7 (29\%) of 24 epithelioid mesotheliomas and none of the 7 biphasic mesotheliomas investigated were CL-4 positive, whereas all $23(100 \%)$ metastatic adenocarcinomas expressed this marker. A subsequent study published in 2007 by Facchetti et al, ${ }^{89}$ using the same anti-CL-4 antibody, reported expression in 248 $(88 \%)$ of 278 primary carcinomas of various sites and 57 (98\%) of 58 serosal metastases, whereas all 60 epithelioid, 11 biphasic, and 9 sarcomatoid mesotheliomas were negative. Only a few studies have been published on CL-4 expression in renal cell carcinomas. ${ }^{89,92}$ In one of these investigations, CL-4 expression was demonstrated in $7(87.5 \%)$ of 8 clear cell, $6(100 \%)$ of 6 papillary, and $7(100 \%)$ of 7 chromophobe renal cell carcinomas. ${ }^{89}$ These results are comparable with those obtained in this study in which $28(85 \%)$ of 33 clear cell, $10(100 \%)$ of 10 papillary, and $12(100 \%)$ of 12 chromophobe renal cell carcinomas were CL-4 positive. CL-4 has a higher sensitivity for discriminating epithelioid mesotheliomas from metastatic renal cell carcinomas when compared with other broadspectrum carcinoma markers. In a previous study by this author in which several of the latter markers, including Ber-EP4, MOC-31, CD15, BG8, TAG-72, and CEA, were evaluated, it was concluded that CD15 and MOC-31 were the best markers for distinguishing between epithelioid mesotheliomas and renal cell carcinomas. ${ }^{10}$ The sensitivity of these two markers for renal cell carcinoma was rather low, however, as only $50 \%$ and $42 \%$ of these tumors, respectively, were found to be positive for these markers.

At present, a relatively large number of positive mesothelioma markers that can assist in the differential diagnosis between epithelioid mesotheliomas and renal cell carcinomas are currently available. These include calretinin, keratin 5/6, WT1, mesothelin, and thrombomodulin.

Calretinin is one of the positive mesothelioma markers that, because it is commonly expressed in epithelioid mesotheliomas, but not in carcinomas, is usually recommended as one of the primary markers in the various immunohistochemical panels used in the diagnosis of these tumors. ${ }^{91}$ In my experience, as well as that of others, calretinin expression can be demonstrated in nearly all epithelioid mesotheliomas when polyclonal antibodies against recombinant human calretinin are used. ${ }^{6,7,93-95}$ In a combined review of four published studies on calretinin expression in renal cell carcinomas, 5 (2\%) of 204 clear cell, 7 (10\%) of 77 papillary, and 3 $(6 \%)$ of 50 chromophobe renal cell carcinomas were reported to express calretinin. ${ }^{10,96-98}$ That none of the clear cell, papillary, or chromophobe renal cell carcinomas studied in a previous investigation by this author were calretinin positive indicates that this marker is uncommonly expressed in these types of tumors. ${ }^{10}$

Keratin $5 / 6$ is another marker that, similar to calretinin, is expressed in nearly all epithelioid mesotheliomas., ${ }^{7,99}$ In my experience, as well as that of other investigators, however, this marker has been consistently negative in all clear cell, papillary, and chromophobe renal cell carcinomas investigated. ${ }^{10,85,100,101}$

Depending on the antibody used, WT1 expression has been reported in $43-100 \%$ of epithelioid 
mesotheliomas. ${ }^{4,7,95,102,103}$ When the 6F-H2 monoclonal antibody, which reacts with the N-terminal of the WT1 protein, is used, positivity can be demonstrated in over $90 \%$ of epithelioid mesotheliomas. Only a few studies with a relatively small number of cases have been published on WT1 expression in renal cell carcinomas. ${ }^{10,102,104,105}$ In the largest of these studies, which was by this author, WT1 positivity was demonstrated in only $1(4 \%)$ of 24 clear cell, but in none of 8 papillary or 12 chromophobe, renal cell carcinomas included in that investigation. ${ }^{10}$

Mesothelin is a marker that has been reported to be commonly expressed in epithelioid mesotheliomas ( 90-100\%). ${ }^{10,106-109}$ Only a few studies have been published on the expression of this marker in renal cell carcinomas. The first of these was by Frierson et al, ${ }^{110}$ who reported mesothelin positivity in $1(3 \%)$ of 33 renal cell carcinomas. ${ }^{110}$ In a subsequent study, however, I was unable to demonstrate the expression for this marker in any of 44 renal cell carcinomas (24 clear, 8 papillary, 12 chromophobe). ${ }^{10}$ Because all of the 40 epithelioid mesotheliomas included in that investigation exhibited strong mesothelin positivity, it was concluded that this was a highly sensitive and specific marker for discriminating between epithelioid mesotheliomas and renal cell carcinomas.

Thrombomodulin was the first positive mesothelioma marker that became generally accepted as being useful in assisting in the differential diagnosis of epithelioid mesothelioma. The percentage of thrombomodulin positivity reported in these tumors ranged from $\sim 50$ to $100 \%$ of the cases. ${ }^{3,7,10,93,95,111-113}$ Several studies have also investigated the expression of this marker in renal cell carcinomas. ${ }^{8-10,114}$ One of these was in 2002 by Osborn et al, ${ }^{9}$ who reported thrombomodulin expression in $13(33 \%)$ of 40 renal cell carcinomas and concluded that this marker has no utility in distinguishing between these tumors and epithelioid mesotheliomas. This is in contrast to two previous studies by other investigators in which all 28 renal cell carcinomas included in those investigations were negative for this marker. 8,114 In a more recent study by this author, only $1(2 \%)$ of 44 renal cell carcinomas was thrombomodulin positive. ${ }^{10}$

The results of the present investigation indicate that, because of their sensitivity and specificity, CL-4 and PAX8 should be considered to be the best positive carcinoma markers. In renal cell carcinomas, positivity for CL-4 and PAX8 was demonstrated in $91 \%$ and $89 \%$ of the cases, respectively, while all of the mesotheliomas were negative for these markers. Because their sensitivity for renal cell carcinomas is lower, PAX2 and napsin A have limited value for assisting in distinguishing these tumors from epithelioid mesotheliomas. As CA IX is commonly expressed in both renal cell carcinomas and epithelioid mesotheliomas, it has no value in discriminating between these malignancies. Finally, since the International Mesothelioma Interest
Group $^{115}$ recommends an immunohistochemical panel composed of two positive carcinoma markers and two positive mesothelioma markers for distinguishing between epithelioid mesotheliomas and metastatic carcinomas to the serosal membranes, based on the findings of this study, as well as the results obtained in previous investigations by this author, CL-4 and PAX8 combined with keratin 5/6 and calretinin (or mesothelin) will usually make it possible to distinguish epithelioid mesotheliomas from metastatic renal cell carcinomas. In addition, if the differential diagnosis between pleural mesothelioma and metastatic renal cell carcinoma includes other tumors with features resembling these two types of neoplasms, such as solid adenocarcinomas and squamous cell carcinomas of the lung with clear cell morphology, and papillary serous carcinomas of the ovary, some other markers, such as thyroid transcription factor 1 , p63, and estrogen receptor, which are commonly expressed in adenocarcinomas of the lung, squamous cell carcinomas, and papillary serous carcinomas, respectively, but not in epithelioid mesotheliomas or renal cell carcinomas, could be added to the immunohistochemical panel. ${ }^{10,116-118}$

\section{Disclosure/conflict of interest}

The authors declare no conflict of interest.

\section{References}

1 Ordóñez NG. The immunohistochemical diagnosis of mesothelioma. Differentiation of mesothelioma and lung adenocarcinoma. Am J Surg Pathol 1989;13: 276-291.

2 Wick MR, Loy T, Mills SE, et al. Malignant epithelioid pleural mesothelioma versus peripheral pulmonary adenocarcinoma: a histochemical, ultrastructural, and immunohistologic study of 103 cases. Hum Pathol 1990;21:759-766.

3 Brown RW, Clark GM, Tandon AK, et al. Multiplemarker immunohistochemical phenotypes distinguishing malignant pleural mesothelioma from pulmonary adenocarcinoma. Hum Pathol 1993;24: 347-354.

4 Oates J, C Edwards. HBME-1, MOC-31, WT1 and calretinin: as assessment of recently described markers for mesothelioma and adenocarcinoma. Histopathology 2000;36:341-347.

5 Carella R, Deleonardi G, D'Errico A, et al. Immunohistochemical panels for differentiating epithelial malignant mesothelioma from lung adenocarcinoma: a study with logistic regression analysis. Am J Surg Pathol 2001;25:43-50.

6 Comin CE, Novelli L, Boddi V, et al. Calretinin, thrombomodulin, CEA, and CD15: a useful combination of immunohistochemical markers for differentiating pleural epithelial mesothelioma from peripheral pulmonary adenocarcinoma. Hum Pathol 2001;32:529-536. 
7 Ordóñez NG. The immunohistochemical diagnosis of mesothelioma: a comparative study of epithelioid mesothelioma and lung adenocarcinoma. Am J Surg Pathol 2003;27:1031-1051.

8 Attanoos RL, Goddard H, Thomas ND, et al. A comparative immunohistochemical study of malignant mesothelioma and renal cell carcinoma: the diagnostic utility of Leu-M1, Ber EP4, Tamm-Horsfall protein and thrombomodulin. Histopathology 1995;27:361-366.

9 Osborn M, Pelling N, Walker MM, et al. The value of 'mesothelium-associated' antibodies in distinguishing between metastatic renal cell carcinomas and mesotheliomas. Histopathology 2002;41:301-307.

10 Ordóñez NG. The diagnostic utility of immunohistochemistry in distinguishing between mesothelioma and renal cell carcinoma: a comparative study. Hum Pathol 2004;35:697-710.

11 Cavazza A, Pasquinelli G, Agostini L, et al. Foamy cell mesothelioma. Histopathology 2002;41:369-371.

12 Ordóñez NG. Mesothelioma with clear cell features: an ultrastructural and immunohistochemical study of 20 cases. Hum Pathol 2005;36:465-473.

13 Latour A, Shulman HS. Thoracic manifestations of renal cell carcinoma. Radiology 1976;121:43-48.

14 Taylor DR, Page W, Hughes D, et al. Metastatic renal cell carcinoma mimicking pleural mesothelioma. Thorax 1987;42:901-902.

15 Azuma T, Nishimatsu H, Nakagawa T, et al. Metastatic renal cell carcinoma mimicking pleural mesothelioma. Scand J Urol Nephrol 1999;33:140-141.

16 Attanoos RL, Gibbs AR. 'Pseudomesotheliomatous' carcinomas of the pleura: a 10-year analysis of cases from the Environmental Lung Disease Research Group, Cardiff. Histopathology 2003;43:444-452.

17 Ohnishi $\mathrm{H}$, Abe M, Hamada H, et al. Metastatic renal cell carcinoma presenting as multiple pleural tumours. Respirology 2005;10:128-131.

18 Mandel JS, McLaughlin JK, Schlehofer B, et al. International renal-cell cancer study. IV. Occupation. Int J Cancer 1995;61:601-605.

19 Sali D, Boffetta P. Kidney cancer and occupational exposure to asbestos: a meta-analysis of occupational cohort studies. Cancer Causes Control 2000;11:37-47.

20 Roberts GH. Distant visceral metastases in pleural mesothelioma. Br J Dis Chest 1976;70:246-250.

21 Truong LD, Shen SS. Immunohistochemical diagnosis of renal neoplasms. Arch Pathol Lab Med 2011;135:92-109.

22 Stoykova A, Gruss P. Roles of Pax-genes in developing and adult brain as suggested by expression patterns. J Neurosci 1994;14:1395-1412.

23 Mittag J, Winterhager E, Bauer K, et al. Congenital hypothyroid female pax8-deficient mice are infertile despite thyroid hormone replacement therapy. Endocrinology 2007;148:719-725.

24 Tong GX, Yu WM, Beaubier NT, et al. Expression of PAX8 in normal and neoplastic renal tissues: an immunohistochemical study. Mod Pathol 2009;22:1218-1227.

25 Ozcan A, Shen SS, Hamilton C, et al. PAX 8 expression in non-neoplastic tissues, primary tumors, and metastatic tumors: a comprehensive immunohistochemical study. Mod Pathol 2011;24: 751-764

26 Tacha D, Zhou D, Cheng L. Expression of PAX8 in normal and neoplastic tissues: a comprehensive immunohistochemical study. Appl Immunohistochem Mol Morphol 2011;19:293-299.

27 Fujiwara M, Taube J, Sharma M, et al. PAX8 discriminates ovarian metastases from adnexal tumors and other cutaneous metastases. J Cutan Pathol 2010;37:938-943.

28 Carney EM, Banerjee P, Ellis CL, et al. PAX2(-)/ PAX8( $(-)$ /inhibin $\mathrm{A}(+)$ immunoprofile in hemangioblastoma: a helpful combination in the differential diagnosis with metastatic clear cell renal cell carcinoma to the central nervous system. Am J Surg Pathol 2011;35:262-267.

29 Sangoi AR, Fujiwara M, West RB, et al. Immunohistochemical distinction of primary adrenal cortical lesions from metastatic clear cell renal cell carcinoma: a study of 248 cases. Am J Surg Pathol 2011;35:678-686.

30 Laury AR, Hornick JL, Perets R, et al. PAX8 reliably distinguishes ovarian serous tumors from malignant mesothelioma. Am J Surg Pathol 2010;34:627-635.

31 Ordóñez NG. Value of PAX 8 immunostaining in tumor diagnosis: a review and update. Adv Anat Pathol 2012;19:140-151.

32 Torres M, Gómez-Pardo E, Dressler GR, et al. Pax-2 controls multiple steps of urogenital development. Development 1995;121:4057-4065.

33 Dressler GR, Woolf AS. Pax2 in development and renal disease. Int J Dev Biol 1999;43:463-468.

34 Daniel L, Lechevallier E, Giorgi R, et al. Pax-2 expression in adult renal tumors. Hum Pathol 2001;32:282-287.

35 Gupta R, Balzer B, Picken M, et al. Diagnostic implications of transcription factor Pax 2 protein and transmembrane enzyme complex carbonic anhydrase IX immunoreactivity in adult renal epithelial neoplasms. Am J Surg Pathol 2009;33:241-247.

36 Zhai QJ, Ozcan A, Hamilton C, et al. PAX-2 expression in non-neoplastic, primary neoplastic, and metastatic neoplastic tissue: a comprehensive immunohistochemical study. Appl Immunohistochem Mol Morphol 2010;18:323-332.

37 Mazal PR, Stichenwirth M, Koller A, et al. Expression of aquaporins and PAX-2 compared to CD10 and cytokeratin 7 in renal neoplasms: a tissue microarray study. Mod Pathol 2005;18:535-540.

38 Memeo L, Jhang J, Assaad AM, et al. Immunohistochemical analysis for cytokeratin 7, KIT, and PAX2: value in the differential diagnosis of chromophobe cell carcinoma. Am J Clin Pathol 2007;127:225-229.

39 Wasco MJ, Pu RT. Comparison of PAX-2, RCC antigen, and antiphosphorylated H2AX antibody (gamma-H2AX) in diagnosing metastatic renal cell carcinoma by fine-needle aspiration. Diagn Cytopathol 2008;36:568-573.

40 Ozcan A, Zhai J, Hamilton C, et al. PAX-2 in the diagnosis of primary renal tumors: immunohistochemical comparison with renal cell carcinoma marker antigen and kidney-specific cadherin. Am J Clin Pathol 2009;131:393-404.

41 Carvalho JC, Wasco MJ, Kunju LP, et al. Cluster analysis of immunohistochemical profiles delineates CK7, vimentin, S100A1 and C-kit (CD117) as an optimal panel in the differential diagnosis of renal oncocytoma from its mimics. Histopathology 2011;58:169-179.

42 Sharma SG, Gokden M, McKenney JK, et al. The utility of PAX-2 and renal cell carcinoma marker 
immunohistochemistry in distinguishing papillary renal cell carcinoma from nonrenal cell neoplasms with papillary features. Appl Immunohistochem Mol Morphol 2010;18:494-498.

43 Gokden N, Gokden M, Phan DC, et al. The utility of PAX-2 in distinguishing metastatic clear cell renal cell carcinoma from its morphologic mimics: an immunohistochemical study with comparison to renal cell carcinoma marker. Am J Surg Pathol 2008;32:1462-1467.

44 Rivera AL, Takei H, Zhai J, et al. Useful immunohistochemical markers in differentiating hemangioblastoma versus metastatic renal cell carcinoma. Neuropathology 2010;30:580-585.

45 Tong GX, Chiriboga L, Hamele-Bena D, et al. Expression of PAX2 in papillary serous carcinoma of the ovary: immunohistochemical evidence of fallopian tube or secondary Müllerian system origin? Mod Pathol 2007;20:856-863.

46 Ordóñez NG. Value of PAX2 Immunostaining in tumor diagnosis: a review and update. Adv Anat Pathol 2012;19:401-409.

47 Ordóñez NG. Napsin A expression in lung and kidney neoplasia: a review and update. Adv Anat Pathol 2012;19:66-73.

48 Mori K, Shimizu H, Konno A, et al. Immunohistochemical localization of napsin and its potential role in protein catabolism in renal proximal tubules. Arch Histol Cytol 2002;65:359-368.

49 Argani P, Hicks J, De Marzo AM, et al. Xp11 translocation renal cell carcinoma (RCC): extended immunohistochemical profile emphasizing novel RCC markers. Am J Surg Pathol 2010;34:1295-1303.

50 Bishop JA, Sharma R, Illei PB. Napsin A and thyroid transcription factor-1 expression in carcinomas of the lung, breast, pancreas, colon, kidney, thyroid, and malignant mesothelioma. Hum Pathol 2010;41: 20-25.

51 Stoll LM, Johnson MW, Gabrielson E, et al. The utility of napsin-A in the identification of primary and metastatic lung adenocarcinoma among cytologically poorly differentiated carcinomas. Cancer Cytopathol 2010;118:441-449.

52 Ye J, Findeis-Hosey JJ, Yang Q, et al. Combination of napsin A and TTF-1 immunohistochemistry helps in differentiating primary lung adenocarcinoma from metastatic carcinoma in the lung. Appl Immunohistochem Mol Morphol 2011;19:313-317.

53 Hirano T, Gong Y, Yoshida K, et al. Usefulness of TA02 (napsin A) to distinguish primary lung adenocarcinoma from metastatic lung adenocarcinoma. Lung Cancer 2003;41:155-162.

54 Dejmek A, Naucler P, Smedjeback A, et al. Napsin A (TA02) is a useful alternative to thyroid transcription factor-1 (TTF-1) for the identification of pulmonary adenocarcinoma cells in pleural effusions. Diagn Cytopathol 2007;35:493-497.

55 Amatya VJ, Takeshima Y, Kohno H, et al. Caveolin-1 is a novel immunohistochemical marker to differentiate epithelioid mesothelioma from lung adenocarcinoma. Histopathology 2009;55:10-19.

56 Sly WS, Hu PY. Human carbonic anhydrases and carbonic anhydrase deficiencies. Annu Rev Biochem 1995;64:375-401.

57 Potter CP, Harris AL. Diagnostic, prognostic and therapeutic implications of carbonic anhydrases in cancer. Br J Cancer 2003;89:2-7.
58 Robertson N, Potter C, Harris AL. Role of carbonic anhydrase IX in human tumor cell growth, survival, and invasion. Cancer Res 2004;64:6160-6165.

59 Liao SY, Aurelio ON, Jan K, et al. Identification of the MN/CA9 protein as a reliable diagnostic biomarker of clear cell carcinoma of the kidney. Cancer Res 1997;57:2827-2831.

60 Tostain J, Li G, Gentil-Perret A, et al. Carbonic anhydrase 9 in clear cell renal cell carcinoma: a marker for diagnosis, prognosis and treatment. Eur J Cancer 2010;46:3141-3148.

61 Leppert JT, Lam JS, Pantuck AJ, et al. Carbonic anhydrase IX and the future of molecular markers in renal cell carcinoma. BJU Int 2005;96:281-285.

62 Leibovich BC, Sheinin Y, Lohse CM, et al. Carbonic anhydrase IX is not an independent predictor of outcome for patients with clear cell renal cell carcinoma. J Clin Oncol 2007;25:4757-4764.

63 Al-Ahmadie HA, Alden D, Qin LX, et al. Carbonic anhydrase IX expression in clear cell renal cell carcinoma: an immunohistochemical study comparing 2 antibodies. Am J Surg Pathol 2008;32:377-382.

64 Genega EM, Ghebremichael M, Najarian R, et al. Carbonic anhydrase IX expression in renal neoplasms: correlation with tumor type and grade. Am J Clin Pathol 2010;134:873-879.

65 McKenney JK, Fujiwara M, Higgins JP, et al. Comparison of putative renal cell carcinoma (RCC) immunohistochemical (IHC) markers in primary adrenal cortical lesions (ACL) and metastatic RCC: a tissue microarray study of 246 cases. Mod Pathol 2009;22(Suppl 1):182A.

66 Osunkoya AO, Yin-Goen Q, Phan JH, et al. Diagnostic biomarkers for renal cell carcinoma: selection using novel bioinformatics systems for microarray data analysis. Hum Pathol 2009;40:1671-1678.

67 Lapinski JE, Chen L, Zhou M. Distinguishing clear cell renal cell carcinoma, retroperitoneal paraganglioma, and adrenal cortical lesions on limited biopsy material: utility of immunohistochemical markers. Appl Immunohistochem Mol Morphol 2010;18:414-421.

68 Prayson RA, Chamberlain WA, Angelov L. Clear cell meningioma: a clinicopathologic study of 18 tumors and examination of the use of CD10, CA9, and RCC antibodies to distinguish between clear cell meningioma and metastatic clear cell renal cell carcinoma. Appl Immunohistochem Mol Morphol 2010;18: 422-428.

69 Ramsey ML, Yuh BJ, Johnson MT, et al. Carbonic anhydrase IX is expressed in mesothelioma and metastatic clear cell renal cell carcinoma of the lung. Virchows Arch 2012;460:89-93.

70 Ivanov S, Liao SY, Ivanova A, et al. Expression of hypoxia-inducible cell-surface transmembrane carbonic anhydrases in human cancer. Am J Pathol 2001;158:905-919.

71 Yoshida SO, Imam A. Monoclonal antibody to a proximal nephrogenic renal antigen: immunohistochemical analysis of formalin-fixed, paraffin-embedded human renal cell carcinomas. Cancer Res 1989;49:1802-1809.

72 Avery AK, Beckstead J, Renshaw AA, et al. Use of antibodies to RCC and CD10 in the differential diagnosis of renal neoplasms. Am J Surg Pathol 2000;24:203-210. 
73 Pan CC, Chen PC, Ho DM. The diagnostic utility of MOC31, BerEP4, RCC marker and CD10 in the classification of renal cell carcinoma and renal oncocytoma: an immunohistochemical analysis of 328 cases. Histopathology 2004;45:452-459.

74 McGregor DK, Khurana KK, Cao C, et al. Diagnosing primary and metastatic renal cell carcinoma: the use of the monoclonal antibody 'renal cell carcinoma marker'. Am J Surg Pathol 2001;25:1485-1492.

75 Butnor KJ, Nicholson AG, Allred DC, et al. Expression of renal cell carcinoma-associated markers erythropoietin, CD10, and renal cell carcinoma marker in diffuse malignant mesothelioma and metastatic renal cell carcinoma. Arch Pathol Lab Med 2006;130:823-827.

76 Bakshi N, Kunju LP, Giordano T, et al. Expression of renal cell carcinoma antigen (RCC) in renal epithelial and nonrenal tumors: diagnostic implications. Appl Immunohistochem Mol Morphol 2007;15:310-315.

77 Allory Y, Bazille C, Vieillefond A, et al. Profiling and classification tree applied to renal epithelial tumours. Histopathology 2008;52:158-166.

78 Pan CC, Chen PC, Tsay SH, et al. Differential immunoprofiles of hepatocellular carcinoma, renal cell carcinoma, and adrenocortical carcinoma: a systemic immunohistochemical survey using tissue array technique. Appl Immunohistochem Mol Morphol 2005;13:347-352.

79 Ingold B, Wild PJ, Nocito A, et al. Renal cell carcinoma marker reliably discriminates central nervous system haemangioblastoma from brain metastases of renal cell carcinoma. Histopathology 2008;52:674-681.

80 Yan M, Ghorab Z, Nadji M. Renal cell carcinoma antigen is expressed by yolk sac tumors and yolk sac elements of embryonal carcinomas. Appl Immunohistochem Mol Morphol 2003;11:113-115.

81 Ritz J, Pesando JM, Notis-McConarty J, et al. A monoclonal antibody to human acute lymphoblastic leukaemia antigen. Nature 1980;283:583-585.

82 McCluggage WG, Sumathi VP, Maxwell P. CD10 is a sensitive and diagnostically useful immunohistochemical marker of normal endometrial stroma and of endometrial stromal neoplasms. Histopathology 2001;39:273-278.

83 Xiao SY, Wang HL, Hart J, et al. cDNA arrays and immunohistochemistry identification of CD10/ CALLA expression in hepatocellular carcinoma. Am J Pathol 2001;159:1415-1421.

$84 \mathrm{Kim}$ MK, Kim S. Immunohistochemical profile of common epithelial neoplasms arising in the kidney. Appl Immunohistochem Mol Morphol 2002;10: 332-338.

85 Langner C, Ratschek M, Rehak P, et al. CD10 is a diagnostic and prognostic marker in renal malignancies. Histopathology 2004;45:460-467.

86 Martignoni G, Pea M, Brunelli M, et al. CD10 is expressed in a subset of chromophobe renal cell carcinomas. Mod Pathol 2004;17:1455-1463.

87 Paner GP, Srigley JR, Radhakrishnan A, et al. Immunohistochemical analysis of mucinous tubular and spindle cell carcinoma and papillary renal cell carcinoma of the kidney: significant immunophenotypic overlap warrants diagnostic caution. Am J Surg Pathol 2006;30:13-19.

88 Liu L, Qian J, Singh H, et al. Immunohistochemical analysis of chromophobe renal cell carcinoma, renal oncocytoma, and clear cell carcinoma: an optimal and practical panel for differential diagnosis. Arch Pathol Lab Med 2007;131:1290-1297.

89 Facchetti F, Lonardi S, Gentili F, et al. Claudin 4 identifies a wide spectrum of epithelial neoplasms and represents a very useful marker for carcinoma versus mesothelioma diagnosis in pleural and peritoneal biopsies and effusions. Virchows Arch 2007;451:669-680.

90 Soini Y, Kinnula V, Kahlos K, et al. Claudins in differential diagnosis between mesothelioma and metastatic adenocarcinoma of the pleura. J Clin Pathol 2006;59:250-254.

91 Ordóñez NG. Application of immunohistochemistry in the diagnosis of epithelioid mesothelioma: a review and update. Hum Pathol 2012;44:1-19.

92 Soini Y. Expression of claudins 1, 2, 3, 4, 5 and 7 in various types of tumours. Histopathology 2005;46: 551-560.

93 Doglioni C, Dei Tos AP, Laurino L, et al. Calretinin: a novel immunocytochemical marker for mesothelioma. Am J Surg Pathol 1996;20:1037-1046.

94 Ordóñez NG. Value of calretinin immunostaining in differentiating epithelial mesothelioma from lung adenocarcinoma. Mod Pathol 1998;11:929-933.

95 Miettinen M, Limon J, Niezabitowski A, et al. Calretinin and other mesothelioma markers in synovial sarcoma: analysis of antigenic similarities and differences with malignant mesothelioma. Am J Surg Pathol 2001;25:610-617.

96 Martignoni G, Pea M, Chilosi M, et al. Parvalbumin is constantly expressed in chromophobe renal carcinoma. Mod Pathol 2001;14:760-767.

97 Lugli A, Forster Y, Haas P, et al. Calretinin expression in human normal and neoplastic tissues: a tissue microarray analysis on 5233 tissue samples. Hum Pathol 2003;34:994-1000.

98 Chu AY, Litzky LA, Pasha TL, et al. Utility of D2-40, a novel mesothelial marker, in the diagnosis of malignant mesothelioma. Mod Pathol 2005;18: 105-110.

99 Ordóñez NG. Value of cytokeratin 5/6 immunostaining in distinguishing epithelial mesothelioma of the pleura from lung adenocarcinoma. Am J Surg Pathol 1998;22:1215-1221.

100 Nolan LP, Heatley MK. The value of immunocytochemistry in distinguishing between clear cell carcinoma of the kidney and ovary. Int J Gynecol Pathol 2001;20:155-159.

101 Skinnider BF, Folpe AL, Hennigar RA, et al. Distribution of cytokeratins and vimentin in adult renal neoplasms and normal renal tissue: potential utility of a cytokeratin antibody panel in the differential diagnosis of renal tumors. Am J Surg Pathol 2005;29:747-754.

102 Ordóñez NG. Value of thyroid transcription factor-1, E-cadherin, BG8, WT1, and CD44S immunostaining in distinguishing epithelial pleural mesothelioma from pulmonary and nonpulmonary adenocarcinoma. Am J Surg Pathol 2000;24:598-606.

$103 \mathrm{Pu}$ RT, Pang Y, Michael CW. Utility of WT-1, p63, MOC31, mesothelin, and cytokeratin (K903 and CK5/ 6) immunostains in differentiating adenocarcinoma, squamous cell carcinoma, and malignant mesothelioma in effusions. Diagn Cytopathol 2008;36:20-25.

104 Muir TE, Cheville JC, Lager DJ. Metanephric adenoma, nephrogenic rests, and Wilms' tumor: a histologic 
and immunophenotypic comparison. Am J Surg Pathol 2001;25:1290-1296.

105 Chute DJ, Kong CS, Stelow EB. Immunohistochemistry for the detection of renal cell carcinoma in effusion cytology. Diagn Cytopathol 2011;39:118-123.

106 Miettinen M, Sarlomo-Rikala M. Expression of calretinin, thrombomodulin, keratin 5, and mesothelin in lung carcinomas of different types: an immunohistochemical analysis of 596 tumors in comparison with epithelioid mesotheliomas of the pleura. Am J Surg Pathol 2003;27:150-158.

107 Ordóñez NG. Application of mesothelin immunostaining in tumor diagnosis. Am J Surg Pathol 2003;27:1418-1428.

108 Ordóñez NG. Value of mesothelin immunostaining in the diagnosis of mesothelioma. Mod Pathol 2003;16:192-197.

109 Galloway ML, Murray D, Moffat DF. The use of the monoclonal antibody mesothelin in the diagnosis of malignant mesothelioma in pleural biopsies. Histopathology 2006;48:767-769.

110 Frierson HF Jr, Moskaluk CA, Powell SM, et al. Largescale molecular and tissue microarray analysis of mesothelin expression in common human carcinomas. Hum Pathol 2003;34:605-609.

111 Collins CL, Ordóñez NG, Schaefer R, et al. Thrombomodulin expression in malignant pleural mesothelioma and pulmonary adenocarcinoma. Am J Pathol 1992;141:827-833.

112 Ordóñez NG. Value of antibodies 44-3A6, SM3, HBME-1 and thrombomodulin in differentiating epithelial pleural mesothelioma from lung adenocarcinoma: a comparative study with other commonly used antibodies. Am J Surg Pathol 1997;21: 1399-1408.

113 Riera JR, Astengo-Osuna C, Longmate JA, et al. The immunohistochemical diagnostic panel for epithelial mesothelioma: a reevaluation after heat-induced epitope retrieval. Am J Surg Pathol 1997;21: 1409-1419.

114 Kennedy AD, King G, Kerr KM. HBME-1 and antithrombomodulin in the differential diagnosis of malignant mesothelioma of pleura. J Clin Pathol 1997;50:859-862.

115 Husain AN, Colby T, Ordóñez N, et al. Guidelines for pathologic diagnosis of malignant mesothelioma: 2012 update of the consensus statement from the International Mesothelioma Interest Group. Arch Pathol Lab Med 2012 (e-pub ahead of print).

116 Ordóñez NG. Value of estrogen and progesterone receptor immunostaining in distinguishing between peritoneal mesotheliomas and serous carcinomas. Hum Pathol 2005;36:1163-1167.

117 Ordóñez NG. The diagnostic utility of immunohistochemistry in distinguishing between epithelioid mesotheliomas and squamous carcinomas of the lung: a comparative study. Mod Pathol 2006;19: 417-428.

118 Ordóñez NG. Value of PAX8, PAX2, claudin-4, and h-caldesmon immunostaining in distinguishing peritoneal epithelioid mesotheliomas from serous carcinomas. Mod Pathol 2012 (e-pub ahead of print). 